Nomelini, QSS, Cunha, NSS, Fernandes, RM, Oliveira, RR, Santos, CCR \& Aguena, MS. (2020). School Bullying and the Perception of Mato Grossense Students. Research, Society and Development, 9(7):1-21, e272973865.

\title{
Bullying e a percepção dos estudantes Mato-Grossenses
}

School bullying and the perception of Mato Grossense students Acoso escolar y la percepción de estudiantes de Mato Grossense

Recebido: 22/04/2020 | Revisado: 29/04/2020 | Aceito: 05/05/2020 | Publicado: 12/05/2020

Quintiliano Siqueira Schroden Nomelini

ORCID: http://orcid.org/0000-0002-1738-2151

Universidade Federal de Uberlândia, Brasil

E-mail: quintilianonomelini@gmail.com

Natália Sathler de Souza Cunha

ORCID: http://orcid.org/0000-0002-8572-6550

Universidade Federal de Uberlândia, Brasil

E-mail: sathlerdesouzacunha@gmail.com

Raquel Martins Fernandes

ORCID: http://orcid.org/0000-0002-0317-5389

Instituto Federal de Mato Grosso, Brasil

E-mail: raquel.fernandes@blv.ifmt.edu.br

Rodrigo Ribeiro de Oliveira

ORCID: http://orcid.org/0000-0002-1006-6500

Instituto Federal de São Paulo, Brasil

E-mail: rodrigoribeirosp@hotmail.com

\section{Carla Cristina Rodrigues Santos}

ORCID: http://orcid.org/0000-0002-5608-523X

Instituto Federal de Mato Grosso, Brasil

E-mail: carlarsantos2019@gmail.com

Miguel Shiniti Aguena

ORCID: http://orcid.org/0000-0003-1811-4391

Instituto Federal de São Paulo, Brasil

E-mail: miguel.aguena737@gmail.com 


\title{
Resumo
}

O bullying é a prática da violação dos direitos humanos que constrange e inferioriza suas vítimas. Metade das crianças e jovens do mundo já sofreu algum tipo de bullying. No Brasil, cerca de $43 \%$ da população dos escolares vivencia ameaças, opressão, intimidação, humilhação e maus-tratos. O objetivo da pesquisa é a percepção dos estudantes do Ensino Básico quanto ao bullying. O estudo é quantitativo e de cunho descritivo, utilizando-se do software Statistical Package for the Social Sciences - SPSS para a análise dos dados coletados. Nesta pesquisa participaram 271 estudantes, sendo de duas escolas públicas e uma particular do Estado do Mato Grosso. Identificou-se que aproximadamente $25 \%$ e $55 \%$ dos alunos das escolas públicas e particulares, respectivamente, sofreram alguma violação de seus direitos no ambiente escolar. Entre as agressões se destacam apelidos, insultos pelas características físicas e as agressões físicas. Conclui-se que tais dados confirmam a emergência de ações de conscientização e de prevenção da violência e mostram a necessidade de incluir no currículo das escolas essas ações.

Palavras-chave: Bullying; Percepção; Estudantes; Ensino Básico.

\begin{abstract}
Bullying is the practice of violating human rights that embarrasses and inferiorizes its victims. Half of the world's children and youth have already suffered some form of bullying. In Brazil, about $43 \%$ of the population of students experiences threats, oppression, intimidation, humiliation and mistreatment. The objective of the research is the perception of Basic Education students regarding bullying. The study is quantitative and of a descriptive nature, using the Statistical Package for the Social Sciences SPSS software for the analysis of the collected data. 271 students participated in this research, being from two public schools and a private one from the State of Mato Grosso. It was identified that approximately $25 \%$ and $55 \%$ of students from public and private schools, respectively, suffered some violation of their rights in the school environment. Among the assaults stand out nicknames, insults for the physical characteristics and the physical assaults. It is concluded that such data confirm the emergence of awareness and violence prevention actions and show the need to include these actions in the schools curriculum.
\end{abstract}

Keywords: Bullying; Perception; Students; Basic Education.

\section{Resumen}

La intimidación es la práctica de violar los derechos humanos que avergüenza e inferioriza a sus víctimas. La mitad de los niños y jóvenes del mundo ya han sufrido alguna forma de acoso escolar. En Brasil, alrededor del $43 \%$ de la población de estudiantes experimenta amenazas, opresión, intimidación, humillación y maltrato. El objetivo de la investigación es la percepción de los estudiantes de Educación Básica sobre el acoso escolar. El estudio es cuantitativo y descriptivo, 
utilizando el paquete estadístico para las ciencias sociales - software SPSS para el análisis de los datos recopilados. 271 estudiantes participaron en esta investigación, provenientes de dos escuelas públicas y una privada del estado de Mato Grosso. Se identificó que aproximadamente el 25\% y el 55\% de los estudiantes de escuelas públicas y privadas, respectivamente, sufrieron alguna violación de sus derechos en el entorno escolar. Entre los asaltos destacan los apodos, los insultos por las características físicas y los asaltos físicos. Se concluye que dichos datos confirman el surgimiento de acciones de concientización y prevención de la violencia y muestran la necesidad de incluir estas acciones en el currículo escolar.

Palabras clave: Intimidación Percepción Estudiantes; Educacion Basica.

\section{Introdução}

Pesquisa realizada pelas Nações Unidas, em 2016, mostrou que, em média, metade das crianças e jovens do mundo já sofreu algum tipo de bullying por razões, como: aparência física, gênero, orientação sexual, etnia ou país de origem. No Brasil, esse percentual é de $43 \%$, taxa semelhante a outros países da região: Argentina (47,8\%), Chile (33,2\%), Uruguai (36,7\%) e Colômbia (43,5\%) (UN, 2016).

Em 2016, o Grupo de Pesquisa em Humanidades e Sociedade Contemporânea do Instituto Federal de Educação Ciência e Tecnologia de Mato Grosso deu início à pesquisa "Violação dos Direitos Humanos e bullying no Contexto Escolar: Diagnóstico e Proposta de Intervenção com Base no Empoderamento dos Alunos". Há índices demonstrados nos trabalhados e artigos apresentados e publicados, pelo grupo de pesquisa citado, de um número crescente de casos de bullying abrangendo a faixa etária de alunos que cursam Ensino Médio.

O presente estudo objetivou conhecer a percepção dos estudantes quanto ao bullying, envolvendo estudantes do Ensino Médio, a partir de 271 (sujeitos) estudantes regularmente matriculados em duas escolas públicas (federais) e uma particular do Estado do Mato Grosso, que participaram da investigação, buscando, de forma geral, contribuir para iniciativa de ações imediatas da comunidade escolar para conscientização e para o combate dessas violações.

O Inciso III do Artigo $1^{\text {o }}$ da Constituição Federal de 1988 garante a preservação da dignidade humana, assegurando a todo ser humano direitos básicos e fundamentais, objetivando que o cidadão tenha condições de sobreviver com uma vida digna. Quando se fala em vida digna se refere à liberdade de qualquer indivíduo exercer sua cidadania livre de 
quaisquer ameaças a sua paz e tranquilidade. Diante deste contexto, as práticas de bullying ferem a lei maior, que ainda em seu Artigo $5^{\circ}$ traz que: "Todos são iguais perante a lei, sem distinção de qualquer natureza", garantindo, aos brasileiros e aos estrangeiros residentes no país, a inviolabilidade do direito à vida, à liberdade, à segurança e à propriedade (Brasil, 1988).

Para Silva, Mota e Campos (2019), os processos de escolarização são marcados por etapas diversas de um desenvolvimento psicossocial, alguns fatos e intervenções podem interferir neste processo significativamente, entre esses se destaca a violência escolar, como forte elemento que despotencializa os resultados.

Enquanto muitos estudantes aprendem, em ambientes seguros e estimulantes, outros são expostos à violência e ao bullying, o que infringe seu direito fundamental à educação.

Diante disso, pode-se dizer que o bullying é então uma prática de violação dos direitos humanos, uma vez que esse constrange e inferioriza seus alvos (Fante, 2005). A palavra bullying é um verbo que tem origem inglesa bully, que significa tirano, valentão, brigão. Quando se pontua a prática do dia a dia das escolas do Brasil, esse termo é entendido como ameaça, tirania, opressão, intimidação, humilhação e maltrato.

$\mathrm{Na}$ ocorrência do bullying, geralmente, há duas ou mais pessoas envolvidas. Substancialmente, funciona assim: uma ou mais intimida - autor(es) - e outra é intimidada alvo. Pode haver também uma outra que seja intimidada e também intimida - alvo/autor - e um público - espectador(res). Essas categorias citadas são as mais propensas, porém de acordo com a cultura e a área de atuação dos autores pode haver mais tipificações, tornandose um pouco mais subjetivo, dependendo do contexto em que ocorrem as agressões (Felizardo, 2019).

Segundo Olweus (1993), pioneiro nos estudos referentes ao bullying, o ato de bullying possui características específicas e marcantes, que não o deixa ser confundido com demais tipos de violência, pois esse ocorre na maioria das vezes de forma intencional, repetitiva e há geralmente desequilíbrio de poder. É intencional, pois as ações são direcionadas a determinada pessoa, ou seja, não acontecem por acaso. É repetitivo e muitas vezes contínuo, pois geralmente acontece mais de três vezes com a mesma pessoa. E há desequilíbrio de poder em relação ao tamanho, força física, pois geralmente o autor é maior e mais forte fisicamente, e há divergência na quantidade que, em muitos casos, são dois, três ou mais indivíduos contra uma única pessoa. Assim, ficam evidentes suas características e tipificações, que contribuem muito para a identificação em âmbito escolar. 
Para Silva e Costa (2016), discutir violência em âmbito escolar implica enxergar a escola como espaço social, local de interação social e construção de ethos. Conforme Silva (2019), o bullying é um fenômeno que vem sendo estudado por vários pesquisadores mundialmente e em várias esferas da sociedade (bullying familiar, racista, no trabalho, em grupos sociais).

Segundo Silva e Bazon (2017), a boa convivência no ambiente escolar representa um desafio, pois como na escola se reflete o pluralismo da sociedade, as diferenças pessoais, étnicas/culturais e econômicas podem originar conflitos.

Conforme Pequeno da Silva et al. (2019) se pode constatar que os estudos indicam que os casos de bullying influenciam, direta e negativamente, no desenvolvimento escolar como também na saúde do educando.

Em suma, o ambiente escolar também deve ser um lugar de respeito aos direitos humanos, e não se deve permitir, de forma nenhuma, essas violações, por isso é essencial ações emergentes que vão além dos conteúdos curriculares ministrados.

Ademais, Freire (1990) enfatiza a escola como um espaço de ensino-aprendizagem, como um centro de debates de ideias, respeitando as diversidades de cada um, com foco na formação cidadã e não apenas na conceituação pragmática de conteúdo.

\section{Metodologia}

O percurso deste trabalho foi orientado para uma abordagem quantitativa e de cunho descritivo, segundo Lakatos \& Marconi (2009), a pesquisa quantitativa-descritiva consiste em investigações de pesquisa empírica, cuja principal finalidade é o delineamento ou análise das características ou fenômenos, a avaliação de programas, ou o isolamento de variáveis principais ou chave.

Para a coleta de dados foi utilizado um questionário composto por treze questões, sendo onze objetivas e duas subjetivas; disponibilizado de forma online, através do Google Drive, as questões permitiram que os estudantes respondessem após o assentimento e consentimento dos pais, cuja pesquisa aprovada seguiu as orientações e as condições condizentes ao Comitê de Ética em Pesquisa ( $n^{\circ}$ Parecer: 2.110.377). O questionário possui perguntas sobre o perfil do aluno, suas características socioeconômicas, se o mesmo já sofreu violação dos direitos humanos e os tipos de bullying e níveis de ocorrência da violência, bem como se o mesmo já foi agressor; nas questões abertas, o estudante poderia relatar casos presenciados de bullying e dar sugestões para o enfrentamento do problema. As perguntas 
permitiram um diagnóstico geral da violência escolar nos ambientes pesquisados, o que no presente artigo é analisado quantitativamente, a partir de análise estatística.

Para estimar a proporção populacional amostral encontrada se utilizou um intervalo de confiança exato para o estimador de máxima verossimilhança de " $p$ ", neste utiliza-se a distribuição $F$ (Leemis \& Trivedi, 1996). O intervalo de confiança (IC) para proporção $(p)$ populacional é apresentado a seguir:

$$
I C(p)_{1-\alpha}:[L I ; L S]:\left[\frac{1}{1+\frac{n-y+1}{y F_{2 y ; 2(n-y+1) ;} \frac{1-\alpha}{2}}} ; \frac{1}{\left.1+\frac{n-y}{(y+1) F_{2(y+1) ; 2}(n-y) x_{2}}\right]}\right] \text {, }
$$

em que $L I$ é o limite inferior e $L S$ o limite superior do intervalo de confiança estimado, $1-\alpha$ é o nível de confiança da fórmula 1 , sendo que foi fixado em $95 \%, \alpha$ é o nível de significância, $F$ se refere à probabilidade $\frac{\pi}{2} \mathrm{e} \frac{1-a}{2}$ da cauda superior direita da distribuição de $F ; n$ é o tamanho da amostra, $y$ o número de sucessos $(y=1,2, \ldots, n-1), 2 y$, $2(n-y+1), 2(y+1)$ e $2(n-y)$ são os graus de liberdade das distribuições de $F$.

Segundo Leemis e Trivedi (1996), nos casos especiais, em que $y=0$ e $y=n$ se deve proceder da seguinte forma:

Se $y=0$, o $L I$ do $I C$ é tomado como 0 e o $L S$ é obtido como anteriormente.

Se $y=n$, o $L S$ do $I C$ é tomado como 1 e o $L I$ é obtido como anteriormente.

Como os dados da variável idade não seguem uma distribuição normal de probabilidade, ou seja, não simétrica, uma aproximação para o intervalo de confiança de $1-\alpha$ para a mediana foi estimado pelo método de interpolação de Hettmansperger-Sheather (1986):

$$
I C(M d)_{1-a}:(L I ; L S):\left(\lambda X_{k+1}+(1-\lambda) X_{k} ; \lambda K_{n-k}+(1-\lambda)_{n-k+1}\right),(2)
$$

em que $n$ : tamanho da amostra de uma variável aleatória; $k$ : inteiro entre $\left[0, \frac{n}{2}\right]$; $\lambda=\frac{(n-k) I}{k}+(n-2 k) I ; I=\gamma_{k}-1-\frac{\alpha}{\gamma_{k}}-\gamma_{k+1} ; \gamma_{k+1}<1-\alpha<\gamma_{k} X$ : valores observados.

Como o questionário envolve uma quantidade considerável de perguntas, cada pergunta foi considerada uma variável, e se sabe que neste tipo de situação se podem ter várias perguntas medindo um mesmo campo ou fator, então foi proposta uma Análise Fatorial 
(AF) para redução da dimensão do questionário em alguns fatores. A AF é formada por um conjunto de técnicas estatísticas e possui como objetivo reduzir o número de variáveis iniciais com a menor perda possível de informação. As primeiras pesquisas realizadas, nesta área, foram desenvolvidas por Karl Pearson e por Charles Spearman. De acordo com Vicini (2005), a AF não se refere, apenas, a uma técnica estatística, mas a um conjunto de técnicas relacionadas, para tornar os dados observados mais claros para a interpretação. Isso é feito ao se analisar os inter-relacionamentos entre as variáveis, de tal modo que essas possam ser descritas convenientemente por um grupo de categorias básicas, em número menor que as variáveis originais, chamados fatores, os quais podem ser denominados como um constructo. $\mathrm{Na}$ análise, esses fatores explicam a variância das variáveis observadas, tal como se revelam pelas correlações entre as variáveis, que estão sendo analisadas.

O método mais conhecido para se obter os fatores é o método de componentes principais (ACP). A ACP é uma técnica da estatística multivariada, introduzida por Karl Pearson, em 1901, e foi fundamentada em um trabalho de Hotelling em 1933. Hottelling concentrou seus estudos nas componentes que tinham a maior variabilidade de pontos, ou seja, que respondiam a maior parte da variabilidade dos dados sob estudo, daí o nome Principal acoplado ao próprio nome da técnica (Andriotti, 1997).

Essa metodologia tem como objetivo transformar um conjunto de variáveis originais em um outro conjunto de novas variáveis, linearmente dependentes das variáveis originais, porém não correlacionadas entre si. As novas variáveis são denominadas Componentes Principais (CP).

O cálculo dos CP's ocorre por meio da matriz de variância-covariância, ou a matriz de correlação, das quais são obtidos os autovalores e autovetores. Com esses é possível obter as combinações lineares que se tonaram as novas variáveis, ou seja, os componentes principais. Cada CP é uma combinação linear de todas as variáveis originais, independentes entre si e estimadas com o propósito de reter esses componentes, em ordem de estimação e em termos de variação total, contida nos dados iniciais (Regazzi, 2001). É importante ressaltar que essas matrizes de variância-covariância e de correlação são calculadas através da matriz originária $X$ de dimensão nxp, sendo que $x_{1}, x_{2}, \ldots, x_{p}$ representam as variáveis originais, e cada uma das $n$ unidades experimentais representa os indivíduos, tratamentos, etc.

Para a validação dos itens do questionário e para a redução de dimensão desse foram utilizadas técnicas multivariadas de análise fatorial e componentes principais. As perguntas foram agrupadas por meio de análise fatorial, buscando assim a redução da dimensão dos 
dados multivariados, ou seja, identificar fontes subjacentes de variação comuns a duas ou mais variáveis com mesmo padrão de resposta e, com isso, compreender padrões de intercorrelações (Lattin, Carroll \& Green, 2011). Em seguida, foram realizados os testes de Kaiser-Meyer-Olkin (KMO) e de Esfericidade de Bartlett para verificar se a aplicação da AF tem validade nos dados estudados.

O teste de Scree Plot que, segundo Hair et al. (2005): “é usado para identificar o número ótimo de fatores que podem ser extraídos antes que a quantia de variância única comece a dominar a estrutura de variância comum". O gráfico de Scree Plot, conhecido como o gráfico de "Cotovelo", foi proposto por Cattell (1966), e apresenta, de maneira informal, a variância explicada por cada componente principal na ordem do maior para o menor. $\mathrm{O}$ princípio do gráfico consiste em determinar um ponto após o qual os autovalores restantes declinam de modo aproximadamente linear, retendo somente aqueles componentes que estão acima do ponto. Portanto, o gráfico de Scree Plot requer um julgamento relativo do valor da variância explicada pelos componentes principais.

Para se chegar aos fatores foi utilizada a rotação do tipo Varimax com extração pelo método das componentes principais. As rotações visam maximizar a correlação de uma determinada variável a um único fator, minimizando o número de variáveis com altas cargas sobre um fator, reforçando a interpretabilidade dos fatores e a validação de um questionário com os itens mais relevantes para o conjunto de dados analisado (Malhotra, 2006).

Os dados foram tratados estatisticamente com o auxílio do software Statistical Package for the Social Sciences - SPSS e Sisvar.

\section{Resultados e Discussão}

\section{Escola pública (federal) - "A"}

\section{Estatística descritiva}

A amostra é composta por 127 estudantes, cujas idades variam de 13 a 20 anos, com a média de 16,81 anos. O teste de Shapiro-Wilk foi significativo, ou seja, a variável idade não segue uma distribuição normal. A maioria dos estudantes está no "terceiro ano Escolar" $(39,4 \%)$, seguido por "quarto ano escolar" (30,7\%); a divisão entre os cursos técnicos é semelhante para 'Química' e 'Meio Ambiente" (40,2 e 55,9\% respectivamente); em relação à orientação sexual, $84,3 \%$ dos estudantes se declaram como "heterossexuais"; quanto à escolaridade da mãe e do pai dos estudantes, 46,5\% e 40,9\% têm o Ensino Médio, 
Research, Society and Development, v. 9, n. 7, e272973865, 2020

(CC BY 4.0) | ISSN 2525-3409 | DOI: http://dx.doi.org/10.33448/rsd-v9i7.3865

respectivamente; 76,\% dos estudantes têm residência própria; $89 \%$ dos estudantes não trabalham; 26\% dos estudantes consideram que já tiveram seus direitos violados por outros estudantes/professores/funcionários da escola e 18,9\% admitem que já violaram o direito de um colega através de ofensas/agressões, conforme dados apresentados na Tabela 1.

Tabela 1. Análise descritiva para os estudantes da Escola pública (federal) - "A".

\begin{tabular}{|c|c|c|c|c|c|}
\hline \multirow[b]{2}{*}{ Variável } & & \multirow[b]{2}{*}{ Estimativa } & \multicolumn{2}{|c|}{ IC de $95 \%$ de confiança } & \multirow[b]{2}{*}{$\mathbf{p}^{1}$} \\
\hline & & & LI & $\mathbf{L S}$ & \\
\hline Idade, mediana (IC) & - & 16,81 & 16 & 17 & $<0,00^{*}$ \\
\hline \multirow{2}{*}{ Sexo } & Masculino & $46(36,22 \%)$ & $27,9 \%$ & $45,2 \%$ & \\
\hline & Feminino & $81(63,78 \%)$ & $54,9 \%$ & $72,1 \%$ & \\
\hline \multirow{4}{*}{ Ano Escolar } & $1^{\circ}$ & $25(19,69 \%)$ & $13,2 \%$ & $27,7 \%$ & \\
\hline & $2^{\circ}$ & $13(10,24 \%)$ & $5,6 \%$ & $16,9 \%$ & \\
\hline & $3^{\circ}$ & $50(39,37 \%)$ & $30,8 \%$ & $48,4 \%$ & \\
\hline & $4^{\circ}$ & $39(30,71 \%)$ & $22,8 \%$ & $39,5 \%$ & \\
\hline \multirow{3}{*}{ Curso Técnico } & Química & $51(41,46 \%)$ & $32,6 \%$ & $50,7 \%$ & \\
\hline & Meio Ambiente & $71(57,72 \%)$ & $48,5 \%$ & $66,6 \%$ & \\
\hline & $\begin{array}{c}\text { Controle } \\
\text { Ambiental }\end{array}$ & $1(0,81 \%)$ & $0,0 \%$ & $4,4 \%$ & \\
\hline \multirow{3}{*}{ Orientação Sexual } & Heterossexual & $107(89,17 \%)$ & $82,2 \%$ & $94,1 \%$ & \\
\hline & Homossexual & $3(2,50 \%)$ & $0,5 \%$ & $7,1 \%$ & \\
\hline & Bissexual & $10(8,33 \%)$ & $4,1 \%$ & $14,8 \%$ & \\
\hline \multirow{4}{*}{ Escolaridade da Mãe } & Fundamental & $11(8,66 \%)$ & $4,4 \%$ & $15 \%$ & \\
\hline & Ensino Médio & $59(46,46 \%)$ & $37,6 \%$ & $55,5 \%$ & \\
\hline & Superior & $28(22,05 \%)$ & $15,2 \%$ & $30,3 \%$ & \\
\hline & Pós-Graduação & $29(22,83 \%)$ & $15,9 \%$ & $31,1 \%$ & \\
\hline \multirow{6}{*}{ Escolaridade do Pai } & $\begin{array}{c}\text { Analfabeto/Sem } \\
\text { estudos }\end{array}$ & $2(1,59 \%)$ & $0,2 \%$ & $5,6 \%$ & \\
\hline & Fundamental & $32(25,40 \%)$ & $18,1 \%$ & $33,9 \%$ & \\
\hline & Ensino Médio & $52(41,27 \%)$ & $32,6 \%$ & $50,4 \%$ & \\
\hline & Curso Técnico & $1(0,79 \%)$ & $0,0 \%$ & $4,3 \%$ & \\
\hline & Superior & $29(23,02 \%)$ & $16 \%$ & $31,4 \%$ & \\
\hline & Pós-Graduação & $10(7,94 \%)$ & $3,9 \%$ & $14,1 \%$ & \\
\hline \multirow{2}{*}{ Residência própria } & Não & $30(23,62 \%)$ & $16,5 \%$ & $32 \%$ & \\
\hline & Sim & $97(76,38 \%)$ & $68 \%$ & $83,5 \%$ & \\
\hline \multirow{2}{*}{ Trabalha } & Não & $113(88,98 \%)$ & $82,2 \%$ & $93,8 \%$ & \\
\hline & Sim & $14(11,02 \%)$ & $6,2 \%$ & $17,8 \%$ & \\
\hline \multirow{2}{*}{ Direitos Violados } & Não & $94(74,02 \%)$ & $65,5 \%$ & $81,4 \%$ & \\
\hline & Sim & $33(25,98 \%)$ & $18,6 \%$ & $34,5 \%$ & \\
\hline \multirow{2}{*}{ Maltratou Alguém } & Não & $103(81,10 \%)$ & $73,2 \%$ & $87,5 \%$ & \\
\hline & Sim & $24(18,90 \%)$ & $12,5 \%$ & $25,7 \%$ & \\
\hline
\end{tabular}

1 Teste Shapiro-Wilk para normalidade.

$2 *$ valor significativos

Fonte: Dados da pesquisa. 


\section{$\underline{\text { Estatística descritiva }}$}

A amostra é composta por 117 estudantes, as idades variam de 14 a $43^{*}$ anos, com média igual a 15,44. O teste de Shapiro-Wilk foi significativo, ou seja, a variável idade não segue uma distribuição normal. A maioria dos estudantes está no "primeiro ano escolar" $(39,4 \%)$, seguido por "quarto ano escolar" (65\%); a divisão entre cursos técnicos é semelhante para "Eletromecânica" e "Automação Industrial" (49,5 e 50,4\% respectivamente); $88,9 \%$ dos estudantes se declaram como "heterossexual"; em relação à escolaridade da mãe e do pai dos estudantes, o mais frequente foi o Ensino Médio com 34,2\% e 37,6\%, respectivamente; 66,7\% dos respondentes têm residência própria; apenas um dos 117 estudantes trabalha; $21,4 \%$ desses estudantes declaram que tiveram seus direitos violados, através de agressões físicas e/ou verbais pelos colegas de classe e/ou funcionários da escola, e $28,2 \%$ desses estudantes declaram que já violaram os direitos de ao menos um colega de classe. Os resultados estão apresentados na Tabela 2.

Tabela 2. Análise descritiva para os estudantes da Escola pública (federal) - "B”. 


\begin{tabular}{|c|c|c|c|c|c|}
\hline \multirow[b]{2}{*}{ Variável } & & \multirow[b]{2}{*}{ Estimativa } & \multicolumn{2}{|c|}{ IC de $95 \%$ de confiança } & \multirow[b]{2}{*}{$\mathbf{p}^{1}$} \\
\hline & & & LI & LS & \\
\hline Idade, mediana (IC) & - & 15,44 & 15 & 15 & $<0,00^{*}$ \\
\hline \multirow{2}{*}{ Sexo } & Masculino & $60(51,28 \%)$ & $41,9 \%$ & $60,6 \%$ & \\
\hline & Feminino & $57(48,72 \%)$ & $39,4 \%$ & $58,1 \%$ & \\
\hline \multirow{2}{*}{ Ano Escolar } & $1^{\circ}$ & $76(64,96 \%)$ & $55,6 \%$ & $73,5 \%$ & \\
\hline & $2^{o}$ & $41(35,04 \%)$ & $26,5 \%$ & $44,4 \%$ & \\
\hline \multirow{2}{*}{ Curso Técnico } & Eletromecânica & $58(49,57 \%)$ & $40,2 \%$ & $59 \%$ & \\
\hline & Automação Industrial & $59(50,43 \%)$ & $41, \%$ & $59,8 \%$ & \\
\hline \multirow{4}{*}{ Orientação Sexual } & Heterossexual & $104(90,43 \%)$ & $83,5 \%$ & $95,1 \%$ & \\
\hline & Homossexual & $2(1,74 \%)$ & $0,2 \%$ & $6,1 \%$ & \\
\hline & Bissexual & $8(6,96 \%)$ & $3 \%$ & $13,2 \%$ & \\
\hline & Transsexual & $1(0,87 \%)$ & $0,0 \%$ & $4,7 \%$ & \\
\hline \multirow{4}{*}{ Escolaridade da Mãe } & Fundamental & $22(18,80 \%)$ & $12,2 \%$ & $27,1 \%$ & \\
\hline & Ensino Médio & $40(34,19 \%)$ & $25,7 \%$ & $43,5 \%$ & \\
\hline & Superior & $28(23,93 \%)$ & $16,2 \%$ & $31,7 \%$ & \\
\hline & Pós-Graduação & $27(23,08 \%)$ & $15,8 \%$ & $31,8 \%$ & \\
\hline \multirow{5}{*}{ Escolaridade do Pai } & Fundamental & $34(29,06 \%)$ & $21 \%$ & $38,2 \%$ & \\
\hline & Ensino Médio & $44(37,61 \%)$ & $28,8 \%$ & $47 \%$ & \\
\hline & Curso Técnico & $1(0,85 \%)$ & $0,0 \%$ & $4,7 \%$ & \\
\hline & Superior & $26(22,22 \%)$ & $15,1 \%$ & $30,8 \%$ & \\
\hline & Pós-Graduação & $12(10,26 \%)$ & $5,4 \%$ & $17,2 \%$ & \\
\hline \multirow{2}{*}{ Residência Própria } & Não & $39(33,33 \%)$ & $24,9 \%$ & $42,6 \%$ & \\
\hline & Sim & $78(66,67 \%)$ & $57,4 \%$ & $75,1 \%$ & \\
\hline \multirow{2}{*}{ Trabalha } & Não & $116(99,15 \%)$ & $95,3 \%$ & $100 \%$ & \\
\hline & Sim & $1(0,85 \%)$ & $0,0 \%$ & $4,8 \%$ & \\
\hline \multirow{2}{*}{ Direitos Violados } & Não & $92(78,63 \%)$ & $70,1 \%$ & $85,7 \%$ & \\
\hline & Sim & $25(21,37 \%)$ & $14,3 \%$ & $29,9 \%$ & \\
\hline \multirow{2}{*}{ Maltratou Alguém } & Não & $84(71,79 \%)$ & $62,7 \%$ & $79,7 \%$ & \\
\hline & Sim & $33(28,21 \%)$ & $20,3 \%$ & $37,3 \%$ & \\
\hline
\end{tabular}

1 Teste Shapiro-Wilk para normalidade.

$2 *$ valor significativos

Fonte: Dados da pesquisa.

\section{Escola particular}

\section{Estatística descritiva}

A amostra é composta por 27 estudantes. As idades variam de 14 a 18 anos, com média igual a 16,07. O teste de Shapiro-Wilk foi significativo, ou seja, a variável idade não segue uma distribuição normal. A maioria dos estudantes está no "segundo ano Escolar" (48,1\%), seguido por "terceiro ano escolar" (37\%); o curso mais frequente é Ensino Médio regular $(70,4 \%) ; 77,8 \%$ dos estudantes se declaram como "heterossexuais"; em relação à escolaridade da mãe dos respondentes, $77,7 \%$ estão na faixa de nível superior ou pós- 
Research, Society and Development, v. 9, n. 7, e272973865, 2020

(CC BY 4.0) | ISSN 2525-3409 | DOI: http://dx.doi.org/10.33448/rsd-v9i7.3865

graduação, já os pais têm os mesmos níveis mais frequentes representando 66,6\%; 74\% dos estudantes têm residência própria; 55,6\% desses estudantes declaram que tiveram seus direitos violados, através de agressões físicas e/ou verbais pelos colegas de classe e/ou funcionários da escola, e 59,3\% declaram que já violaram os direitos de ao menos um colega de classe. Os resultados estão na Tabela 3.

Tabela 3. Análise descritiva para os estudantes da Escola Particular.

\begin{tabular}{|c|c|c|c|c|c|}
\hline \multirow[b]{2}{*}{ Variável } & & \multirow[b]{2}{*}{ Estimativa } & \multicolumn{2}{|c|}{ IC de $95 \%$ de confiança } & \multirow[b]{2}{*}{$\mathbf{P}^{1}$} \\
\hline & & & LI & $\mathbf{L S}$ & \\
\hline Idade, mediana (IC) & - & 16,07 & 15 & 17 & $0,029 *$ \\
\hline \multirow{2}{*}{ Sexo } & Masculino & $13(48,15 \%)$ & $28,7 \%$ & $68,1 \%$ & \\
\hline & Feminino & $14(51,85 \%)$ & $31,9 \%$ & $71,3 \%$ & \\
\hline \multirow{3}{*}{ Ano Escolar } & $1^{\mathrm{o}}$ & $4(14,81 \%)$ & $4,2 \%$ & $33,7 \%$ & \\
\hline & $2^{\circ}$ & $13(48,15 \%)$ & $28,7 \%$ & $68,1 \%$ & \\
\hline & $3^{\circ}$ & $10(37,04 \%)$ & $19,4 \%$ & $57,6 \%$ & \\
\hline \multirow{4}{*}{ Curso Técnico } & $\begin{array}{l}\text { Ensino Médio } \\
\text { regular }\end{array}$ & $19(70,37 \%)$ & $49,8 \%$ & $86,2 \%$ & \\
\hline & Meio Ambiente & $6(22,22 \%)$ & $8,6 \%$ & $42,3 \%$ & \\
\hline & Administração & $1(3,70 \%)$ & $0,1 \%$ & $19 \%$ & \\
\hline & Informática & $1(3,70 \%)$ & $0,1 \%$ & $19 \%$ & \\
\hline \multirow{3}{*}{ Orientação Sexual } & Heterossexual & $21(84,00 \%)$ & $63,9 \%$ & $95,5 \%$ & \\
\hline & Homossexual & $3(12,00 \%)$ & $2,5 \%$ & $31,2 \%$ & \\
\hline & Bissexual & $1(4,00 \%)$ & $0,1 \%$ & $20,4 \%$ & \\
\hline \multirow{4}{*}{ Escolaridade da Mãe } & Fundamental & $1(3,70 \%)$ & $0,1 \%$ & $19,6 \%$ & \\
\hline & Ensino Médio & $5(18,52 \%)$ & $6,6 \%$ & $39,4 \%$ & \\
\hline & Superior & $11(40,74 \%)$ & $23,4 \%$ & $63,1 \%$ & \\
\hline & Pós-Graduação & $10(37,04 \%)$ & $20,2 \%$ & $59,4 \%$ & \\
\hline \multirow{4}{*}{ Escolaridade do Pai } & Fundamental & $4(14,81 \%)$ & $4,2 \%$ & $33,7 \%$ & \\
\hline & Ensino Médio & $5(18,52 \%)$ & $6,3 \%$ & $38,1 \%$ & \\
\hline & Superior & $11(40,74 \%)$ & $2,4 \%$ & $61,2 \%$ & \\
\hline & Pós-Graduação & $7(25,93 \%)$ & $11,1 \%$ & $46,3 \%$ & \\
\hline \multirow{2}{*}{ Residência Própria } & Não & $7(25,93 \%)$ & $11,1 \%$ & $46,3 \%$ & \\
\hline & Sim & $20(74,07 \%)$ & $53,7 \%$ & $88,9 \%$ & \\
\hline \multirow{2}{*}{ Direitos Violados } & Não & $12(44,44 \%)$ & $25,5 \%$ & $64,7 \%$ & \\
\hline & Sim & $15(55,56 \%)$ & $35,3 \%$ & $74,5 \%$ & \\
\hline \multirow{2}{*}{ Maltratou Alguém } & Não & $11(40,74 \%)$ & $22,4 \%$ & $61,2 \%$ & \\
\hline & Sim & $16(59,26 \%)$ & $38,8 \%$ & $77,6 \%$ & \\
\hline
\end{tabular}

${ }^{1}$ Teste Shapiro-Wilk para normalidade.

$2 *$ valor significativos

Fonte: Dados da pesquisa.

\section{Análise Fatorial}

Na Figura 1, gráfico de "cotovelo", observa-se que os autovalores declinam de forma aproximadamente linear após a quinta componente principal. Portanto, quando se analisam os 
autovalores de um conjunto de dados se consegue conhecer de que forma as variâncias da matriz de correlações estão distribuídas. Em outras palavras, os autovalores representam o quanto da variância é explicado pelo fator. Para este estudo foi decidido reter os cinco primeiros componentes principais.

Figura 1. Gráfico do cotovelo.

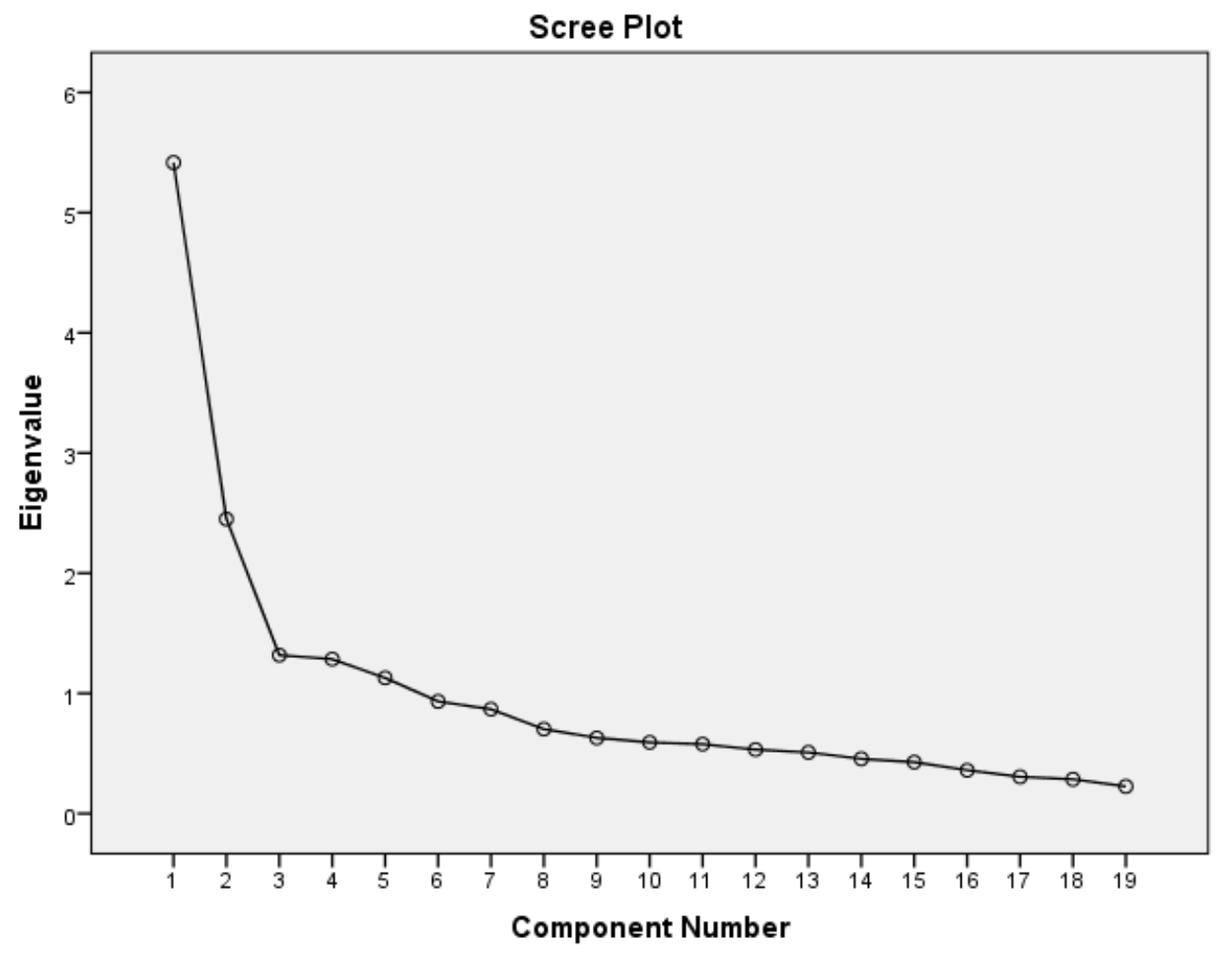

Ao se avaliar a medida de adequação da amostra (KMO), o conjunto de questões atende coletivamente a base necessária de adequação da amostra com o valor de KMO de 0,822 (Hair et al., 2005). Além disso, para aplicação da AF é primordial verificar a pressuposição de Multicolinearidade, ou seja, identificar o conjunto de variáveis interrelacionadas, por meio do teste de Bartlett de Esfericidade (BTS). O teste apresentou uma estatística de qui-quadrado e valor-p igual a 2151,3 $(<0,0001)$, respectivamente, o que caracteriza presença de multicolinearidade, pois $\mathrm{H} 0$ : matriz de correlação = matriz identidade foi rejeitada.

Para determinar quantos fatores devem ser extraídos se verifica a proporção da variância explicada total ou por variável. Estabelece-se um limite e se adota o número de autovalores necessários para o alcance desse limite. Neste estudo, os cinco componentes extraídos explicam $61 \%$ (tabela 4 ). 
A composição dos fatores se baseou na seleção de questões com cargas superiores ou iguais 0,50 , conforme foi destacado na Tabela 4 .

Os dados foram agrupados por meio da análise fatorial e de componentes principais, buscando assim a redução da dimensão dos dados multivariados, ou seja, identificar fontes subjacentes de variação comuns a duas ou mais variáveis com mesmo padrão de resposta e, com isso, compreender padrões de intercorrelações (Lattin, Carroll \& Green, 2011). Para se chegar aos fatores foi utilizada a rotação do tipo Varimax com extração pelo método das componentes principais, as rotações visam maximizar a correlação de uma determinada variável a um único fator, minimizando o número de variáveis com altas cargas sobre um fator, reforçando a interpretabilidade dos fatores (Malhotra, 2006).

A mensuração da fidedignidade dos fatores foi por meio do coeficiente de consistência interna chamado de Alpha de Cronbach, que identifica o grau de covariância entre os itens. Os itens que compõe uma escala devem apresentar um alto valor de alpha, ou seja, este coeficiente varia de 0 a 1 e quanto maior próximo de 1 , maior é a confiabilidade das escalas (Malhotra, 2006; Hair et at., 2005). Segundo Hair et al. (2005), o limite inferior geralmente aceito para o alpha é de 0,70, apesar de poder diminuir para 0,60 em pesquisas exploratórias. Nesse estudo, o Alpha de Cronbach foi de 0,855 .

Foi analisada também a comunalidade de cada fator, a qual é a proporção de variabilidade de cada variável que é explicada pelos fatores. Quanto mais perto a comunalidade estiver de 1 , melhor a variável é explicada pelos fatores.

Tabela 4. Dados da análise fatorial.

\begin{tabular}{lcccccc}
\hline \multicolumn{1}{c}{ Questões } & $\mathbf{1}$ & $\mathbf{2}$ & $\mathbf{3}$ & $\mathbf{4}$ & $\mathbf{5}$ & Comunalidade \\
\hline $\begin{array}{l}\text { Q20 Perseguem-me dentro ou fora } \\
\text { da escola }\end{array}$ & $\mathbf{0 , 8 3 9}$ & & & & 0,723 \\
& & & & & \\
& & & & & \\
\end{tabular}


Research, Society and Development, v. 9, n. 7, e272973865, 2020

(CC BY 4.0) | ISSN 2525-3409 | DOI: http://dx.doi.org/10.33448/rsd-v9i7.3865

Q22 Fui obrigado a entregar meu

dinheiro ou minhas coisas

0,736

0,725

Q18 Forçam-me a agredir outro

colega

$\mathbf{0 , 7 0 7}$

Q17 Encostam-me contra a parede

0,655

0,704

Q09 Inventam que eu furto coisas de meus colegas

0,621

Q13 Ignoram-me completamente,

me dão um "gelo"

0,615

Q11 Não me deixam fazer parte do grupo de amigos

Q08 Fazem com que os outros não gostem de mim

Q07 Riem de mim e me apontam

Q04 Dizem coisas negativas sobre mim ou sobre minha família

Q24 Fazem agressões virtuais (redes sociais)

Q02 Colocam-me apelidos

vergonhosos

Q05 Insultam-me por causa de

alguma característica física

Q01 Insultam-me

Q10 Puxam meu cabelo ou me arranham

Q03 Ameaçam-me

Q15 Pegam meu dinheiro ou minhas coisas sem minha permissão

Q23 Abusam sexualmente de mim

0,778

0,749

0,605

0,694

0,486

0,579

0,550

$\mathbf{0 , 5 4 5}$

0,508

0,501

0,729

$\mathbf{0 , 8 3 7}$

0,677

0,804

0,619

0,669

0,649

0,765

0,584

0,707

0,452

$\mathbf{0 , 5 4 7}$

Q21 Assediam-me sexualmente

$$
\text { \% Variância Total }
$$

\% Variância Total acumulada

KMO

BTS p-valor

Alpha de Cronbach

$28,5 \quad 12,9$

41,4

28,5

$41,4 \quad 48,3$

48,3

$6,9 \quad 6,7$

0,634

$\mathbf{0 , 7 4 9}$

55,1

5,9

0,822

$<0,001$

0,855

As questões ficaram divididas em cinco domínios, de acordo com a Tabela 5.

Tabela 5. Descrição dos fatores.

\begin{tabular}{|c|c|c|}
\hline Fatores & Questões & Descrição \\
\hline $\mathrm{F} 1$ & $\begin{array}{l}\text { Q09 Inventam que eu furto coisas de meus colegas } \\
\text { Q17 Encostam-me contra a parede }\end{array}$ & $\begin{array}{l}\text { Questões relacionadas ao abuso psicológico } \\
\text { podendo chegar a algum tipo de agressão }\end{array}$ \\
\hline
\end{tabular}


Q20 Perseguem-me dentro ou fora da escola

Q22 Fui obrigado a entregar meu dinheiro ou minhas coisas

Q04 Dizem coisas negativas sobre mim ou sobre minha família

Q07 Riem de mim e me apontam

F2

Q08 Fazem com que os outros não gostem de mim

Q11 Não me deixam fazer parte do grupo de amigos

Questões relacionadas aos insultos indiretos,

Q13 Ignoram-me completamente, me dão um "gelo" ataques virtuais

Q24 Fazem agressões virtuais (redes sociais)

Q01 Insultam-me

F3

Q02 Colocam-me apelidos vergonhosos

Q05 Insultam-me por causa de alguma característica física

Q03 Ameaçam-me

F4 Q10 Puxam meu cabelo ou me arranham

Q15 Pegam meu dinheiro ou minhas coisas sem minha permissão

Questões relacionadas aos ataques verbais devido

alguma característica física

Q21 Assediam-me sexualmente

Q23 Abusam sexualmente de mim

Questões relacionadas ao isolamento

do aluno e ameaças

F5

Fonte: Dados da pesquisa.

Ao observar a descrição geral das escolas se percebe que as duas escolas públicas (federais) possuem uma proximidade em relação a alguns percentuais, sendo que, na escola "B”, o nível de escolaridade e o nível socioeconômico, observado pela casa própria são menos elevados que na escola "A"; o número dos que são agredidos e dos que dizem já terem agredido alguém na escola "B" é maior que na escola "A". No entanto, o índice de 'agredidos' e agressores é consideravelmente maior na escola particular, mesmo com alto índice de escolaridade dos pais e da grande parte residirem em casa própria. O padrão de vida e as informações que são vinculadas, na escola particular, podem levar a pensar que o conhecimento sobre bullying e violação dos direitos humanos faz com que os estudantes identifiquem de forma mais acentuada a agressão. De um modo geral, a pesquisa mostrou uma percepção menor do índice de agressão entre as duas escolas públicas (federais), se comparada à escola particular.

Silva (2019) ressalta que as violações de direitos humanos transitam em conjunto e não se classificam e se mensuram isoladamente, sendo necessário analisar todo contexto e complexidade das formas como a violência escolar se apresenta, pois compreende-se que essa não é isolada e descontextualizada. Com embasamento na Lei $\mathrm{n}^{\circ} 13.185 / 2015$, a autora apresenta uma classificação para as ações de violência sistêmica bullying, sendo essas: violência por orientação sexual; violência por aparência física; violência verbal; exclusão social no ambiente escolar; violência física; violência sexual; violência racial; danos materiais e cyberbullying. Na Lei, essas estão agrupadas e associadas aos fatores encontrados na análise estatística (F): - Físico (F4, F1, F5), - Verbal (F2, F3), - Psicológico/Moral (F1, F5, F2), - 
Material (F1, F4), - Virtual (F2) (Brasil, 2015).

A análise fatorial, cujos resultados são observáveis nas Tabelas 4 e 5 se referem a 24 perguntas, em que os estudantes responderam em relação à ocorrência do bullying, em três opções de resposta: nenhuma vez, algumas vezes, muitas vezes. Através da análise fatorial foi possível perceber que o fator 1, que envolve aspectos físicos, psicológicos e materiais, possui maior índice (variância total); ao passo que o fator 5 possui menor variância total, sendo este último grupo relativo à violência sexual (assédio sexual e abuso sexual), que mesmo com menor variância, uma única ocorrência já é preocupante por ser uma violação grave dos Direitos Humanos.

Uma característica que reforça outros estudos existentes sobre a violência escolar no Brasil (Silva, 2019, Fante, 2005) diz respeito aos fatores 2 e 3, no qual se relacionam as violências verbais, virtuais e de exclusão social, por vezes associadas às características físicas (Q05).

Neste estudo, a comunalidade, estando próxima a 1, significa que melhor a variável é explicada pelos fatores, e este ponto ocorre em relação às questões Q20, Q22, Q02, que envolvem violência psicológica, material e verbal.

Ainda, em conformidade com a referida Lei, em seu Art. $5^{\circ}$ destaca a respeito das ações de incumbência direcionadas às instituições e demais estabelecimentos. "É dever do estabelecimento de ensino, dos clubes e das agremiações recreativas assegurar medidas de conscientização, prevenção, diagnose e combate à violência e à intimidação sistemática (bullying)" (Brasil, 2015).

\section{Considerações Finais}

O presente estudo demonstra os dados de forma estatística, seguido de uma análise dos resultados obtidos, buscando, de forma geral, contribuir para iniciativa de ações imediatas da comunidade escolar para conscientização e combate dessas violações.

Este estudo objetivou conhecer a percepção dos estudantes quanto ao bullying entre estudantes do Ensino Básico. 271 (sujeitos) estudantes regularmente matriculados em duas escolas públicas (federais) e uma particular do Estado do Mato Grosso participaram da investigação, buscando de forma geral, contribuir para iniciativa de ações imediatas da comunidade escolar para conscientização e para o combate dessas violações.

Deste total, 121 afirmaram terem sofrido violação de seus direitos em ambiente escolar (21,3\%); entre esses, o percentual maior se encontra na escola particular (51,85\%), a 
maior incidência de vítimas é do sexo masculino (53,57\%). Entre as agressões, as que atingem um maior percentual são os apelidos (48\%) e os insultos em função de características físicas (48\%), seguidos de dizer coisas negativas sobre a pessoa ou família (34\%) e a agressão física $(12 \%)$.

O bullying afeta negativamente o clima escolar e o desenvolvimento de todos os envolvidos - agressor, vítima e toda a comunidade escolar.

Enquanto muitos estudantes aprendem em ambientes seguros e estimulantes, outros são expostos à violência e ao bullying, o que infringe seu direito fundamental à educação.

Combater todas as formas de bullying presentes no meio educacional, que trazem tantos malefícios aos estudantes, é o principal foco da pesquisa, cujo objetivo envolveu verificar os níveis de violação dos direitos humanos e bullying no contexto escolar, observando-se de alguma forma, como alguns fatores externos, tais como: sexualidade, idade, escolaridade dos pais, podem influenciar nessa violência.

Conclui-se que a compreensão sobre o bullying exige o reconhecimento da violência como elemento social significativo na sociedade contemporânea e perpassa as relações escolares sob formatos diversos.

\section{Agradecimentos}

Fundação de Amparo à Pesquisa do Estado de Mato Grosso (Fapemat)

Pró-Reitoria de Pesquisa, Pós-Graduação e Inovação (PROPRES) do Instituto Federal de Educação, Ciência e Tecnologia de Mato Grosso (IFMT)

\section{Referências}

Andriotti, J. L. S. (1997). Análise de componentes principais: fundamentos de uma técnica de análise de dados multivariada aplicável a dados geológicos. Acta Geológica Leopoldensia, São Leopoldo, 20(44), 27-50.

Brasil. [Constituição (1988)]. Constituição da República Federativa do Brasil de 1988. Brasília, DF: Presidência da República, [2016]. Recuperado em 05 abril, 2020, de http://www.planalto.gov.br/ccivil_03/constituicao/constituicao.htm. 
Brasil. (2015). Presidência da República. Casa Civil. Subchefia para Assuntos Jurídicos. Lei $\mathrm{n}^{\circ} 13.185$, de 6 de novembro de 2015. Institui o Programa de Combate à Intimidação Sistemática (Bullying). Brasília: DOU, 9.11.2015. Recuperado em 30 abril, 2020, de http://www.planalto.gov.br/ccivil_03/_Ato20152018/2015/Lei/L1185.htm.

Cattell, R. B. (1996). The Scree Test for the Number of Factors. Multivariete Behavioral Research, 1, 245-276.

Fante, C. (2005). Fenômeno Bullying: Como prevenir a violência nas escolas e educar para a paz. São Paulo: Verus.

Felizardo, R. A. (2017). Bullying Escolar: prevenção, intervenção e resolução com princípios da justiça restaurativa. Curitiba: Intersaberes.

Ferreira, D. F. (2008). SISVAR: um programa para análises e ensino de estatística. Revista Symposium (Lavras), 6, 36-41.

Freire, P. (1990). Direitos Humanos e educação libertadora: gestão democrática da educação pública na cidade de São Paulo. 1. ed. São Paulo: Paz e Terra.

Hair, J. F., Anderson, R. E., Tatham, R. L., \& Black, W. C. (2005). Análise multivariada de dados. Porto Alegre: Bookman.

IBM. SPSS Statistics 21. IBM. (2012). Software. Recuperado em 21 abril, 2020, de http://www-01.ibm.com/software/analytics/spss/products/statistics/.

Lakatos, E. M., \& Marconi, M. A. Fundamentos de metodologia científica. 6. ed. São Paulo: Atlas, 2009.

Lattin, J., Carroll, J. D., Green, P. E. (2011). Análise de dados multivariados. São Paulo: Cengage Learning.

Leemis, L. M., Trivedi, K. S. (1996). A comparison of approximate interval estimators for the bernoulli parameter. The American Statistician. Alexandria, 50(1), 63-68, Feb. 
Malhotra, N. K. (2006). Pesquisa de marketing: uma orientação aplicada. Porto Alegre: Bookman.

Morettin, L. G. (2009). Estatística básica: probabilidade e inferência. São Paulo: Pearson Prentice Hall.

Olweus, D. (1993). Bullyin at school: What We Know and What We Can Do? Oxford, UK: Blackwell.

Pequeno da Silva, G., Silva, G. P., Fernandes, R. M., \& Moriel Junior, J. G. (2019). Bullying e violência no ambiente escolar: uma revisão de literatura no período de 2015-2019. Revista Eletrônica Acervo Saúde, 11(13), e860. https://doi.org/10.25248/reas.e860.2019

Regazzi, A. J. (2001). Análise Multivariada. Viçosa: Universidade Federal de Viçosa, Centro de Ciências Exatas e Tecnológicas. Departamento de Informática, 2001. 166p. Apostila de disciplina INF 766.

Silva, C. S., \& Costa, B. L. D. (2016). Opressão nas escolas: o bullying entre estudantes do ensino básico. Cadernos de Pesquisa, 46(161), 638-663, jul./set. https://doi.org/10.1590/198053143888

Silva, J. L., \& Bazon, M. R. (2017). Prevenção e enfrentamento do bullying: o papel de professores. Revista Educação Especial, 30(59). https://doi.org/10.5902/1984686X28082

Silva, V. C. G. (2019). Violência escolar, bullying e violação de direitos humanos no cotidiano escolar. / Vanessa Costa Gonçalves Silva._Cuiabá, 2019.112f.

Silva, V. C. G., Mota, R. M. F., \& Campos, M.G. (2019). Bullying e Processos de Escolarização: Diálogos e Perspectivas Pedagógicas. Rev. Ens. Educ. Cienc. Human., 20(3), 237-245. DOI: http://dx.doi.org/10.17921/2447-8733.2019v20n3p237-245

UN - United Nations. (2016). Ending the torment: tackling bullying from the schoolyard to cyberspace. United Nations Publications, New York. 
Vicini, L. (2005). Análise multivariada da teoria à prática. Santa Maria: UFSM, CCNE, 215 p.

Walpole, R. E., Myers, R. H., Myers, S. L., \& Ye, K. (2009). Probabilidade e estatística para engenharia e ciências. São Paulo: Pearson Prentice Hall.

Porcentagem de contribuição de cada autor no manuscrito

Quintiliano Siqueira Schroden Nomelini - 20\%

Natália Sathler de Souza Cunha - 20\%

Raquel Martins Fernandes - 20\%

Rodrigo Ribeiro de Oliveira - 20\%

Carla Cristina Rodrigues Santos $-10 \%$

Miguel Shiniti Aguena - 10\% 